\title{
Solitary scalp metastasis - a rare presentation of hepatocellular carcinoma
}

\author{
Duminda Subasinghe ${ }^{1}$, Chathuranga Tisara Keppetiyagama², Hemantha Sudasinghe ${ }^{1}$, Saman Wadanamby ${ }^{2}$, \\ Niranthi Perera ${ }^{3}$ and Sivasuriya Sivaganesh ${ }^{1,4^{*}}$
}

\begin{abstract}
Introduction: Hepatocellular carcinoma (HCC) is among the commonest cancers in the world. Metastasis is one of the most significant factors affecting prognosis. Common sites of extrahepatic metastases include lungs, regional lymph nodes and less commonly bone.

Case presentation: A 56-year-old male presented with a painless occipital scalp lump of three months duration, with recent rapid enlargement. His skull x-ray showed a lytic lesion over occipital bone and the contrast CT scan of the brain showed a scalp mass with destruction of the adjacent skull. Core biopsy of the lesion revealed a metastatic deposit from a hepatocellular carcinoma.
\end{abstract}

Conclusion: Primary presentation with skeletal metastases are rare in HCC with only a few reported cases. Here we report a case of HCC presenting as a solitary scalp lump.

Key words: Hepatocellular carcinoma, Skull metastasis

\section{Background}

Hepatocellular carcinoma is one of the most prevalent cancers worldwide, especially in Asia and Africa [1]. The high incidence of $\mathrm{HCC}$ in Asia is related to the increased prevalence of chronic viral hepatitis B [2]. HCC commonly metastasises to regional lymph nodes and lungs [3], and less commonly to bone. Cutaneous metastases are extremely rare with only few reports in the literature [4]. Though indicative of a poor prognosis, aggressive early identification and treatment can help improve the quality of life in these patients [4]. Here we describe a patient without previous liver disease presenting with a solitary skull deposit as the first manifestation of HCC.

\section{Case presentation}

A 56-year-old male presented with a painless occipital scalp lump of three months duration, with recent rapid enlargement. There was no history of head

\footnotetext{
* Correspondence: siva.sivaganesh@cantab.net

${ }^{1}$ University Surgical Unit, The National Hospital of Sri Lanka, Colombo, Sri Lanka ${ }^{4}$ Department of Surgery, Faculty of Medicine, Kynsey Road, Colombo 8, Colombo, Sri, Lanka

Full list of author information is available at the end of the article
}

injury and no associated headache or vomiting. Despite a history of significant alcohol consumption for over 15 years there was no history of jaundice or prior liver disease. He was free of upper and lower gastrointestinal symptoms, his appetite was good and there was no weight loss. He was a diabetic for nine years on oral hypoglycaemic therapy. Examination revealed a non-tender, hemispherical, subcutaneous lump over the occipital region (Fig. 1a and b) approximately $10 \mathrm{~cm}$ in diameter. The lump was soft to firm in consistency, non-pulsatile and with no demonstrable cough impulse. His general and systemic examination including the abdomen was otherwise unremarkable with no stigmata of chronic liver disease and no focal neurological signs. His routine blood biochemistry including liver function tests was normal. His skull $x$-ray showed a lytic lesion of the occipital bone. The contrast CT scan of the brain showed a scalp mass with destruction of the adjacent skull vault and intracranial extension but (Fig. 2) no penetration of the meninges. Core biopsy of the lesion revealed a metastatic deposit from a hepatocellular carcinoma. This was confirmed by immunohistochemical analysis demonstrating positivity for alpha fetoproteins and hepar 1 . Subsequent triple phase CT scan of the abdomen (Fig. 3) 


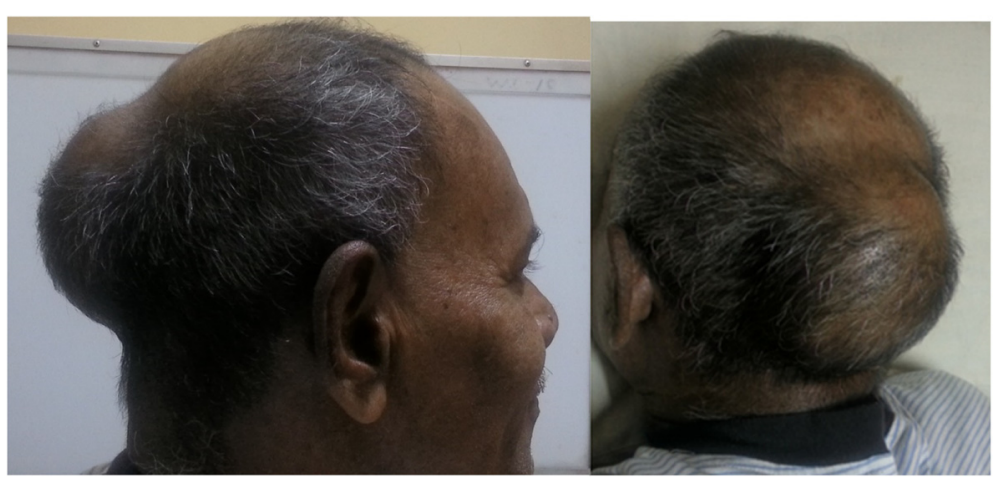

Fig. 1 Occipital scalp lump. a-lateral view, b-posterior view

showed a $3.5 \mathrm{~cm}$ diameter lesion in segment VI of the liver with characteristic features of HCC but no radiological evidence of cirrhosis. His alpha fetoprotein titre was elevated $>392 \mathrm{KU} / \mathrm{l}$ (normal range 0-10 $\mathrm{KU} / \mathrm{l})$. Screening was negative for hepatitis B. His chest $\mathrm{x}$-ray was normal. The patient underwent palliative excision of the scalp deposit to prevent cerebral complications. During surgery the dura mater was found to be intact. The post-operative period was uncomplicated. He subsequently underwent radiofrequency ablation (RFA) of the primary in the liver. During follow up, he developed a painful soft tissue swelling over the left scapular region (Fig. 4a). CT scan revealed a subcutaneous mass with destruction of the left scapula (Fig. 4b), confirmed by FNAC to be metastatic. He was referred to the oncologist for palliative control of this lesion.

\section{Discussion}

Extrahepatic metastases generally occur late in in the course of HCC because most patients succumb to liver failure resulting from of liver parenchymal invasion and replacement by the tumor. Common sites of extrahepatic metastases in HCC include the lungs and to a lesser extent the bone [5]. Skull metastasis is rare with a reported incidence of 0.5-1.6 \% [5-7] and generally occurs in advanced systemic disease. Cutaneous metastases of solid organ malignancies are rare and commonly present after diagnosis of the primary. The incidence of cutaneous metastases in malignancies of the lung, colon, rectum, kidney, bladder and ovary is $3.4 \%-4.0 \%$ [8]. The majority of subcutaneous metastases of $\mathrm{HCC}$ are iatrogenic, occurring in the needle tract of FNAC or in surgical wounds $[9,10]$. There is a paucity of reports on spontaneous subcutaneous deposits possibly because they predominantly present in patients with end stage disease. However, according to Amador et al. it could be the sole and initial presenting feature of HCC [11].

Metastases eroding the vault of the skull may be complicated by epidural haematomas and intratumoral haemorrhage resulting in neurological sequelae $[12,13]$. Excision of the deposit in this patient was done in order to prevent such a complication. RFA of the liver lesion was undertaken since no evidence of further secondary disease was evident at the time (i.e. prior to the identification of the scapular deposit). This is a report of a rare presentation of HCC as a solitary skull metastasis with an asymptomatic primary. Aggressive treatment of local disease and the primary prevents rapid deterioration due to complications and enables a better quality of life in this stage of HCC with an otherwise dismal prognosis.

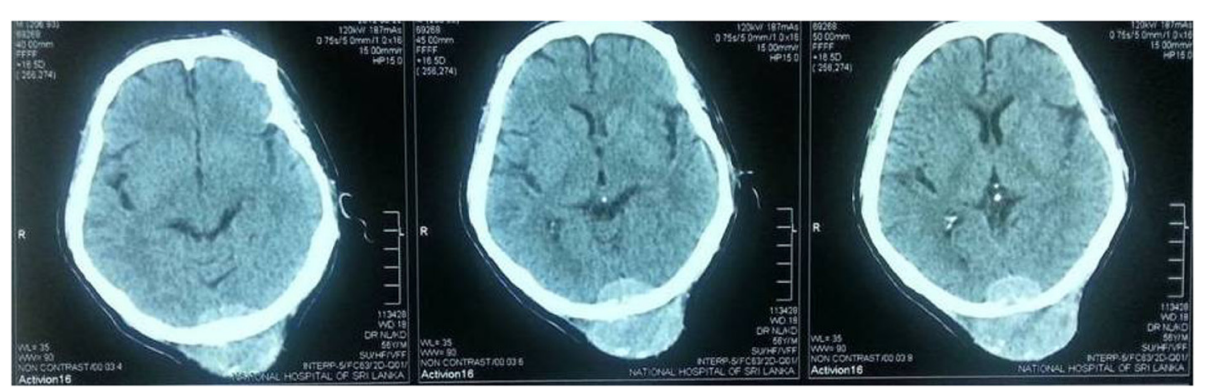

Fig. 2 Contrast CT brain showing skull deposit with extra and intracranial extension 


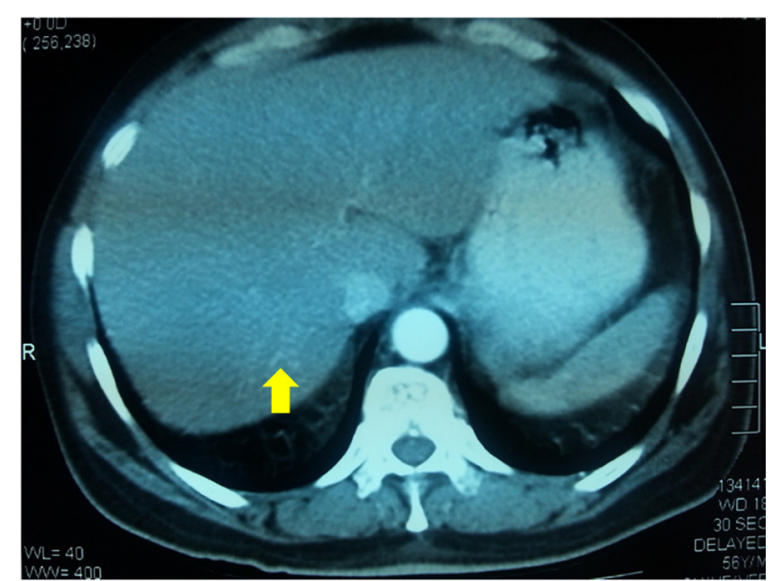

Fig. 3 Contrast CT abdomen showing hepatoma in segment VI

\section{Consent}

Written informed consent was obtained from the patient for publication of this case report and any accompanying images. A copy of the written consent is available for review by the Editor-in-Chief of this journal.
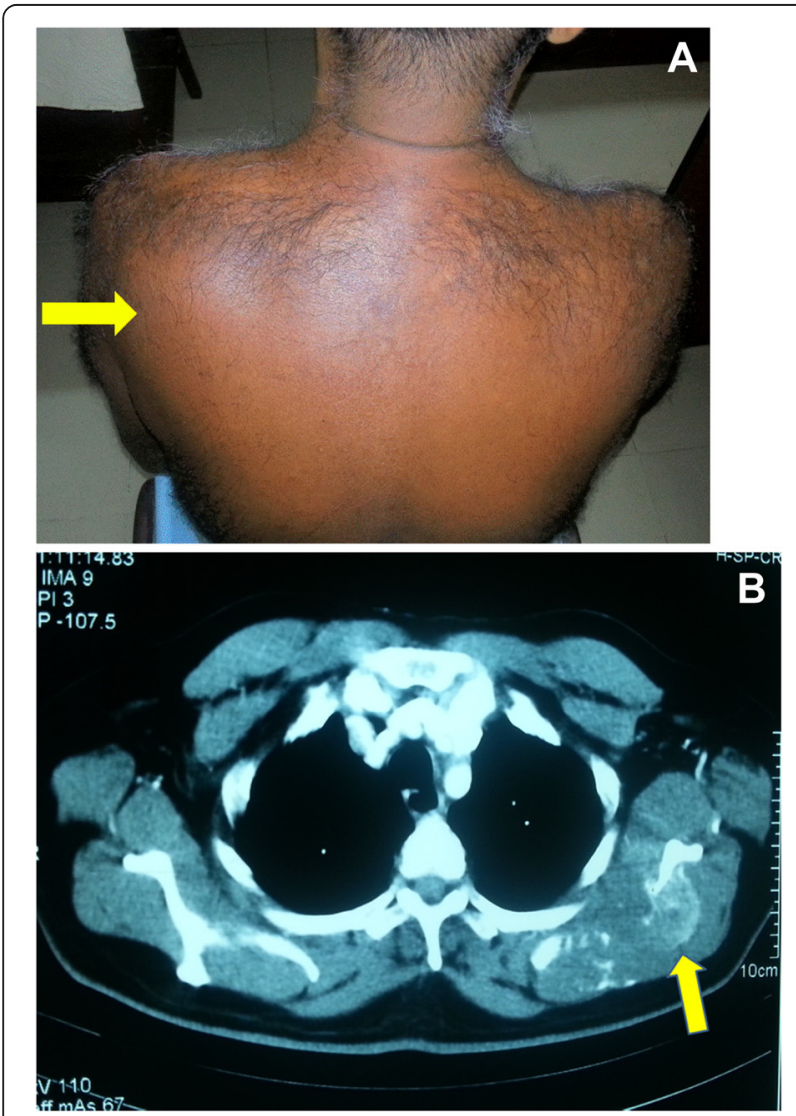

Fig. 4 a Swelling over left scapular region. b Arrow indicates metastatic bone destruction of left scapula

\section{Abbreviations}

HCC: Hepatocellular carcinoma; CT: Computed tomography;

RFA: Radiofrequency ablation; FNAC: Fine needle aspiration cytology.

\section{Competing interests}

The authors declare that they have no competing interests.

\section{Authors' contributions}

SS and DS provided overall supervision and edited the final version of the manuscript. All authors were contributed to management of the patient. All authors have read and approved the final manuscript.

\section{Acknowledgements}

The authors acknowledge all the ward staff who took care of our patient.

\section{Author details}

${ }^{1}$ University Surgical Unit, The National Hospital of Sri Lanka, Colombo, Sri Lanka. ${ }^{2}$ Department of Neurosurgery, The National Hospital of Sri Lanka, Colombo, Sri Lanka. ${ }^{3}$ Department of Pathology, Faculty of Medicine, University of Colombo, Colombo, Sri Lanka. ${ }^{4}$ Department of Surgery, Faculty of Medicine, Kynsey Road, Colombo 8, Colombo, Sri, Lanka.

Received: 24 October 2014 Accepted: 3 June 2015

Published online: 09 June 2015

\section{References}

1. Hsieh CT, Sun JM, Tsai WC, Tsai TH, Chiang YH, Liu MY. Skull metastasis from hepatocellular carcinoma. Acta Neurochir. 2007;149:185-90.

2. Bosch FX, Ribes J, Diaz M, Cleries R. Primary liver cancer; worldwide incidence and trends. Gastroenterology. 2004;127(Suppl1):S5-s16.

3. Yoshida D, Chen MN, Awaya S, Nakazawa S. Cranial metastasis of hepatocellular carcinoma in a female - case report. Neurol Med Chir (Tokyo). 1993;33:839-44.

4. Fukutomi M, Yokota M, Chuman H, Harada H, Zaitsu Y, Funakoshi A, et al. Increased incidence of bone metastases in hepatocellular carcinoma. Eur J Gastroenterol Hepatol. 2001;13:1083-8.

5. Murakami R, Korogi Y, Sakamoto Y, Takhashi M, Okuda T, Yasunaga T, et al. Skull metastasis from hepatocellular carcinoma. CT, MR and angiographic findings. Acta Radiol. 1995;36:597-602.

6. Mclver Jl, Scheithauer BW, Rydberg CH, Atkinson JL. Metastatic hepatocellular carcinoma presenting as epidural hematoma:case report. Neurosurgery. 2001;49:447-9.

7. Chan $\mathrm{CH}$, Trost N, McKelvie P, Rophael JA, Murphy MA. Unusual case of skull metastasis from hepatocellular carcinoma. ANZ I Surg. 2004;74:710-3.

8. Krathen RA, Orengo IF, Rosen T. Cutaneous metastasis: a meta-analysis of data. South Med J. 2003;96:164-7.

9. Casella G, Cacopardo E, Rovere G, Buda CA, Cascinu S, Baldini V. Cutaneous seeding after ultrasound-guided percutaneous ethanol injection for treatment of hepatocellular carcinoma. J Clin Ultrasound. 2001;29:354-8.

10. Koffi E, Moutardier V, Sauvanet A, Noun R, Flejou JF, Belghiti J. Wound recurrence after resection of hepatocellular carcinoma. Liver Tanspl Surg. 1996;2:301-3.

11. Amador A, Monforte NG, Bejarano N, Martí J, Artigau E, Navarro S, et al Cutaneou metastases from hepatocellular carcinoma as the first clinical sign. J Hepatobiliary Pancreat Surg. 2007;14:328-30.

12. Hayashi K, Matsuo T, Kurihara M, et al. Skull metastasis of hepatocellular carcinoma associated with acute epidural haematoma:a case report. Surg Neurol. 2000;53:379-82.

13. Nakagawa Y, Yoshino E, Suzuki K, et al. Spontaneous epidural haematoma from a hepatocellular carcinoma metastasis to the skull. Neurol Med Chir (Tokyo). 1992;32:300-2. 